Communications in Physics, Vol. 30, No. 4 (2020), pp. 391-398

DOI:10.15625/0868-3166/30/4/15422

\title{
SYNTHESIS AND CHARACTERIZATION OF MONODISPERSE HYDROUS COLLOIDAL ZIRCONIA NANOPARTICLES*
}

\author{
NGUYEN THI DIEU LINH ${ }^{1}$, DO QUANG THAM ${ }^{1,2, \dagger}$, NGUYEN VU GIANG $^{1}$, \\ TRAN HUU TRUNG ${ }^{1}$, LE THI MY HANH ${ }^{1}$, NGUYEN THI THU TRANG ${ }^{1}$, \\ NGUYEN THUY CHINH ${ }^{1}$, TRAN THI MAI ${ }^{1}$, THAI HOANG ${ }^{1}$ AND DO VAN SY ${ }^{3}$ \\ ${ }^{1}$ Institute for Tropical Technology, \\ Vietnam Academy of Science and Technology, 18 Hoang Quoc Viet, Cau Giay, Hanoi, Vietnam \\ ${ }^{2}$ Graduate University of Science and Technology, \\ Vietnam Academy of Science and Technology, 18 Hoang Quoc Viet, Cau Giay, Hanoi, Vietnam \\ ${ }^{3}$ Faculty of Chemical Technology, Hanoi University of Industry, \\ Tay Tuu, Bac Tu Liem, Hanoi, Vietnam \\ ${ }^{\dagger}$ E-mail: dqtham@itt.vast.vn
}

Received 27 August 2020

Accepted for publication 06 November 2020

Published 25 November 2020

\begin{abstract}
The suspension of hydrous colloidal zirconia particles (CZPs) was prepared from zirconium oxychloride solutions via thermal hydrolysis at acidic condition and at boiling point of $110^{\circ} \mathrm{C}$ for $72 \mathrm{~h}$. Characterization of the obtained suspension and dried solid $\mathrm{ZrO}_{2}$ was performed by DLS, FESEM, FTIR, XRD and TGA measurements. Purification of the CZP suspension via dialysis membrane can maintain the monodispersion of the colloidal suspension when stabilized at $\mathrm{pH}=6$. The suspension contained almost sheet-like colloidal particles with length from 70 to $140 \mathrm{~nm}$ and thickness of about $50 \mathrm{~nm}$, in semicrystal structure. The formula of hydrous CZPs can be expressed as $\mathrm{ZrO}_{2} \cdot 2 \mathrm{H}_{2} \mathrm{O}$.
\end{abstract}

Keywords: colloidal zirconia, CZPs, monodispersion, zirconium oxychloride.

Classification numbers: 81.07.Wx; 81.16.Be; 81.16.-c; 61.05.cp.

\section{INTRODUCTION}

Zirconia is a kind of ceramic material, this short name stands for zirconium oxide $\left(\mathrm{ZrO}_{2}\right)$, hydrous zirconia $\left(\mathrm{ZrO}_{2} \cdot \mathrm{nH}_{2} \mathrm{O}\right)$ is also a ceramic material, and its properties are similar to zirconia [1-4]. Recently, hydrous zirconia and nanozirconia have attracted a considerable interest

\footnotetext{
* This paper is dedicated to the $40^{\text {th }}$ anniversary of Institute for Tropical Technology

C2020 Vietnam Academy of Science and Technology
} 
for fundamental scientific researches and practical technological applications. Up to now, there have been several methods for preparing hydrous zirconia, including chemical precipitation, solgel route, and thermal hydrolysis synthesis from zirconium salts such as $\mathrm{ZrOCl}_{2}, \mathrm{ZrO}\left(\mathrm{NO}_{3}\right)_{2}$, $\mathrm{ZrOSO}_{4}$ [4-7].

The formation of hydrous CZPs from thermal hydrolysis of $\mathrm{ZrOCl}_{2}$ can be explained by the chemical reaction equation (1) [7-9]. It is worthy to noted that, the conversion rate of hydrous zirconia $\left(\mathrm{ZrO}_{2} \cdot 2 \mathrm{H}_{2} \mathrm{O}\right)$ from $\mathrm{ZrOCl}_{2}$ is very fast with the addition of ammonia, and thus only microparticles can be obtained [3]. Therefore, in order to obtain colloidal nano particles of hydrous zirconia, it is reasonable to carry out the experiment with the addition of $\mathrm{HCl}$. In fact, the milkywhite suspension was slowly generated during boiling the $\mathrm{ZrOCl}_{2}$ solution [10]. This is due to the hydrolysis reaction, as can be expressed in Eq. (1).

$$
\mathrm{ZrOCl}_{2}+(\mathrm{n}+1) \mathrm{H}_{2} \mathrm{O} \rightarrow \mathrm{ZrO}_{2} \cdot \mathrm{n}\left(\mathrm{H}_{2} \mathrm{O}\right)+2 \mathrm{HCl} .
$$

It was also reported that when $\mathrm{ZrOCl}_{2}$ dissolved in aqueous solution, the tetramer units of $\left[\mathrm{Zr}_{4}(\mathrm{OH})_{8}\left(\mathrm{H}_{2} \mathrm{O}\right)_{16}\right]^{8+}$ are dominantly formed. Heating the solution causes the reaction of these unit release $\mathrm{H}^{+}$and the polymerization of these tetramer units. When the concentration of the polymeric species reaches a critical super saturation level, nuclei of hydrous zirconia are generated, primary particles and colloidal particles of hydrous zirconia are formed by growth of the nuclei [11].

At the surface of a colloidal particle, $\mathrm{H}^{+}$ions adsorbed onto the surface-hydroxyl of colloidal particles, as a result, $\mathrm{Cl}$ ions then electrically attracts with these hydroxyl groups to form an electric double layer around a colloidal particle and negative charge can be generated, as can be seen in Eq. (2). This negative charge layers prevent particles to agglomerate and a stable colloidal suspension can be obtained [12-14]

$$
\mathrm{Zr}-\mathrm{OH}+\mathrm{H}^{+}+\mathrm{Cl}^{-} \rightarrow \mathrm{Zr}-\mathrm{OH}_{2}^{+} \mathrm{Cl}^{-} \text {. }
$$

Many reasearch groups applied colloidal processes, the processing methods involving the addition of certain reagents that are absorbed into particles, to avoid agglomeration and achieve stability [15]. Moreover, thermal hydrolysis synthesis is one of the best methods to prepare colloidal zirconia suspensions [8, 10,16-19]. Therefore, this study provides a modified method combining from thermal hydrolysis method and a colloidal process to prepare and stabilize the monodisperse hydrous colloidal zirconia particles. In this study, $\mathrm{ZrOCl}_{2}$ also used as a precursor for preparing of hydrous colloidal zirconia and a purification of colloidal process via using dialysis membrane to maintain the monodispersion of the colloidal zirconia particles in the suspension.

\section{EXPERIMENTAL}

\section{II.1. Materials}

Zirconium oxychloride octahydrate $\left(\mathrm{ZrOCl}_{2} .8 \mathrm{H}_{2} \mathrm{O}, 98 \%\right)$ was purchased from Sigma Aldrich (USA). Nano zirconia $\left(\mathrm{ZrO}_{2} 99.9 \%\right)$ in fine powder form with average particle size of $40 \mathrm{~nm}$ was obtained from Alladins (China), the powder was dried in vacuum oven at $80^{\circ}$ for $24 \mathrm{~h}$ before use. Other chemicals, such as hydrochloride $(\mathrm{HCl} 37 \%)$, methanol $\left(\mathrm{CH}_{3} \mathrm{OH}, 99.7 \%\right)$, ethanol $\left(\mathrm{C}_{2} \mathrm{H}_{5} \mathrm{OH}, 99.7 \%\right)$, silver nitrate $\left(\mathrm{AgNO}_{3}, 99.5 \%\right)$ were reagent grade products of Duc Giang chemical company (Vietnam). 


\section{II.2. Synthesis and purification of colloidal zirconia nanoparticles (CZPs)}

Synthetic procedures: Into a $250 \mathrm{~mL}$ long-neck measuring flask, about $150 \mathrm{~mL}$ of pure water was initially charged; $8.056 \mathrm{~g}$ of $\mathrm{ZrOCl}_{2}$ pentahydrate salt, $4.558 \mathrm{~g}$ of $\mathrm{HCl} 10 \%$ solution were added. The flask was shaken until the salt was fully dissolved, and finally filled with pure water up to the mark on its neck $(250 \mathrm{~mL})$. Concentrations of the solution with $\mathrm{ZrOCl}_{2} 0.1 \mathrm{M}$ and $\mathrm{HCl} 0.05 \mathrm{M}$ were obtained. The solution was then filtered by using a Minisart@syringe filter to remove all unwanted solid particles. The filtered solution was next charged into $500 \mathrm{~mL}$ flask equipped with water cooled condenser and a thermometer. The flask was heated by a mantle oven to reach the boiling point of salt solution $\left(110^{\circ} \mathrm{C}\right)$ and maintained during boiling. After $24 \mathrm{~h}$ milkwhite colloids of hydrous zirconia can be observed, the reaction was allowed for $72 \mathrm{~h} \mathrm{[10]}$. Stable colloidal suspension was finally stored in a glass bottle at room temperature.

Purification process: Due to incomplete reaction and high $\mathrm{HCl}$ concentration, un-reacted zirconium oxychloride and hydrochloric acid were removed from the colloidal solution through dialysis process using cellulose tube molecular weight cut-off $12-14 \mathrm{kDa}$ with period water bath change until $\mathrm{pH}$ of outer water solution reached $7.0 \pm 0.1$ and a negative precipitation of $\mathrm{AgNO}_{3}$ test. The colloidal zirconia suspension was then stabilized at $\mathrm{pH}=6$ by using $1 \% \mathrm{HCl}$ solution. The solid content of hydrous $\mathrm{ZrO}_{2}$ in the colloidal suspension was evaluated by complete drying a certain weight of colloidal suspension gravimetrically, result was calculated as $1.50 \mathrm{wt} \%$. This means that the conversion of $\mathrm{ZrO}_{\mathrm{nH}} \mathrm{O}$ from $\mathrm{ZrOCl}_{2}$ was almost completed if $\mathrm{n}$ takes value of 2 .

\section{II.3. Characterization and methods}

Particles size distribution of colloidal zirconia suspension (at $1 \mathrm{wt} . \%$ solid content) was conducted via dynamic light scattering (DLS) method using a Zetasizer Ver 620 Instrument (Malvern Instruments Ltd.) with laser light source wavelength of $532 \mathrm{~nm}$ at room temperature.

The morphology of investigated sample was observed by using Hitachi Field Emission Scanning Electron Microscopy (FESEM, S-4800) at electron accelerating voltage of $5 \mathrm{kV}$. The samples of CZPs was prepared by depositing one drop of colloidal suspension onto a glass slide, naturally dried, then vacuum dried and finally coated with Pt layer.

Fourier transform infrared (FTIR) spectra of dried CZPs were conducted on a Nicolet/Nexus 670 spectrometer (USA) at room temperature, using $\mathrm{KBr}$ pellet method in the wavenumbers region from 400 to $4000 \mathrm{~cm}^{-1}$ with 32 scans and a resolution of $4 \mathrm{~cm}^{-1}$.

The crystal structures of hydrous zirconia particles after drying at $100^{\circ} \mathrm{C}$ and annealing at $450^{\circ}$ for $6 \mathrm{~h}$ were examined by X-ray diffraction (XRD) on a Bruker-D5005 instrument (Germany) at the Institute of Chemistry and Materials, Military Institute of Science and Technology (Vietnam).

Thermal gravimetric analysis (TGA) measurement was performed on a NETZSCH TG 209F1 thermal analysis instrument from 30 to $700^{\circ} \mathrm{C}$ under nitrogen inert medium with flow rate of $40 \mathrm{~mL} / \mathrm{min}$ and a heating rate of $10{ }^{\circ} \mathrm{C} / \mathrm{min}$.

\section{RESULTS AND DISCUSSION}

\section{III.1. FTIR study}

Figure 1 displays the FTIR spectra of CZPs dried at $100^{\circ}$ and CZPs calcined at $450^{\circ}$ for 6h. The FTIR spectrum of dried CZPs shows some strong absorption peaks centered at 3382 and 
$1624 \mathrm{~cm}^{-1}$, which represents a high content of -OH groups of zirconia even after drying at $100^{\circ}$. The band at $1401 \mathrm{~cm}^{-1}$ can be assigned for the absorption peak of $\mathrm{Zr}-\mathrm{O}(\mathrm{H})-\mathrm{Zr}$ of hydroxyl surface of CZPs [20]. The peaks at 729 and $497 \mathrm{~cm}^{-1}$ with low percentage transmittance shape are the characters of stretching vibration of Zr-O bonds. After calcination, the FTIR spectrum of calcined CZPs exhibits some new bands appeared at 741,577 and $505 \mathrm{~cm}^{-1}$ which are characteristics of $\mathrm{Zr}-$ $\mathrm{O}-\mathrm{Zr}$ stretching mode in crystalline phase of $\mathrm{ZrO}_{2}$ [9]. Moreover, the intensity of water/hydroxyl absorption peaks at 3390 and $1630 \mathrm{~cm}^{-1}$ are much lower than those in FTIR spectrum of dried CZPs, which indicates a removal of water or dehydration of hydrous zirconia to anhydrous zirconia, corresponding to a transition phase of $\mathrm{ZrO}_{2}$ from amorphous to monoclinic crystalline phases. The absorption peaks in the region $3000-3400 \mathrm{~cm}^{-1}$ in the FTIR spectrum of calcined CZPs can be attributed to the surface hydroxyl groups.

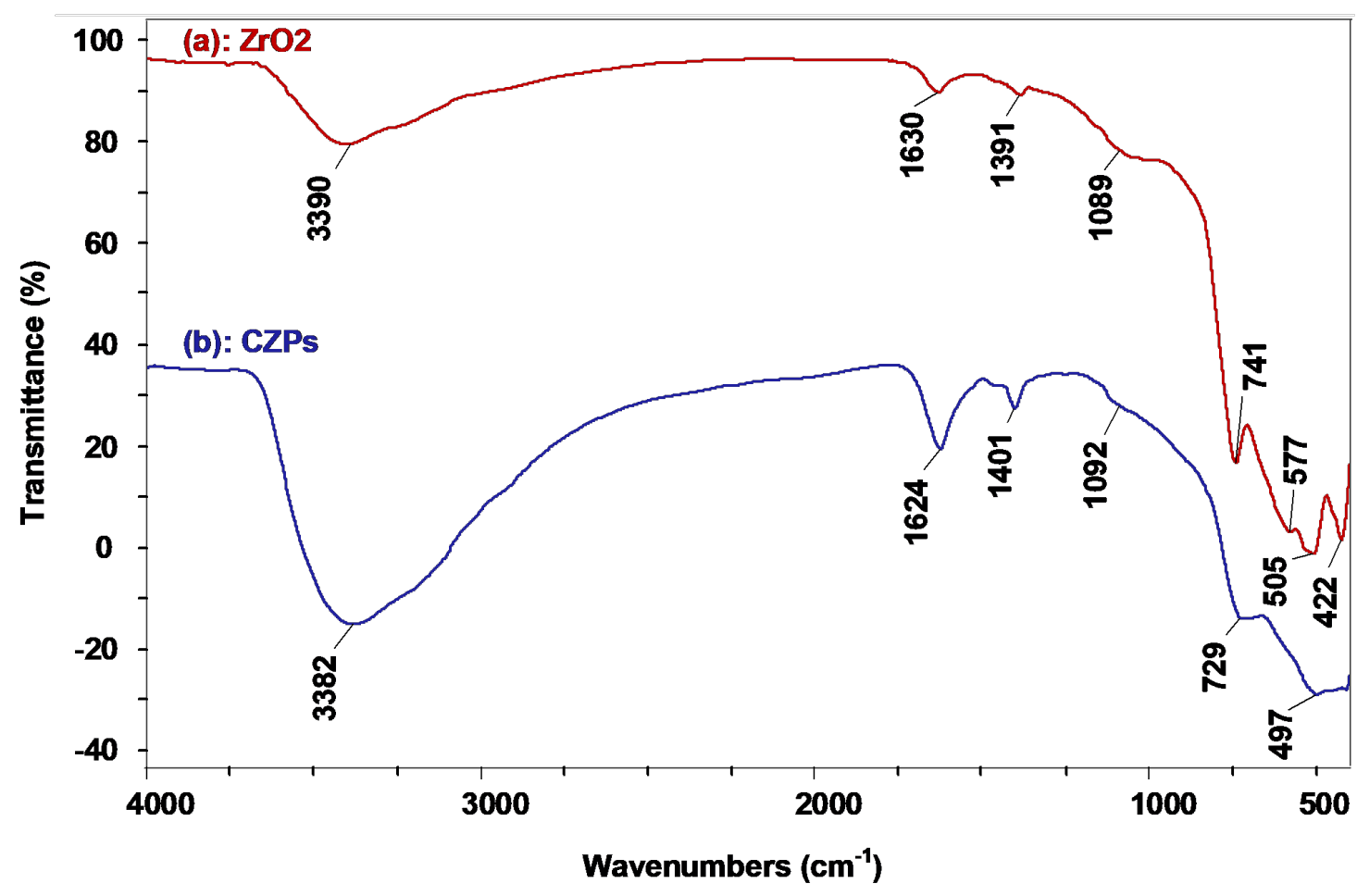

Fig. 1. FTIR spectra of (a): dried CZPs and (b): calcined CZPs at $450^{\circ} \mathrm{C}$ for $6 \mathrm{~h}$.

\section{III.2. DLS and FESEM studies}

Figure 2 displays FESEM images of purified CZPs that were deposited from colloidal zirconia suspension on a glass slide. The FESEM image obviously shows the sheet-like morphology of CZPs with their size ranges from 70 to $140 \mathrm{~nm}$ in length and about $40-60 \mathrm{~nm}$ in thickness.

Figure 3 represents the DLS diagrams of original CZPs (24h after thermal hydrolysis) and the purified CZPs (using dialysis membrane) at $\mathrm{pH}=6$ and with $1 \mathrm{wt} . \%$ concentration of solid content. DLS diagrams clearly show that both types of CZPs have mono dispersion characteristic 

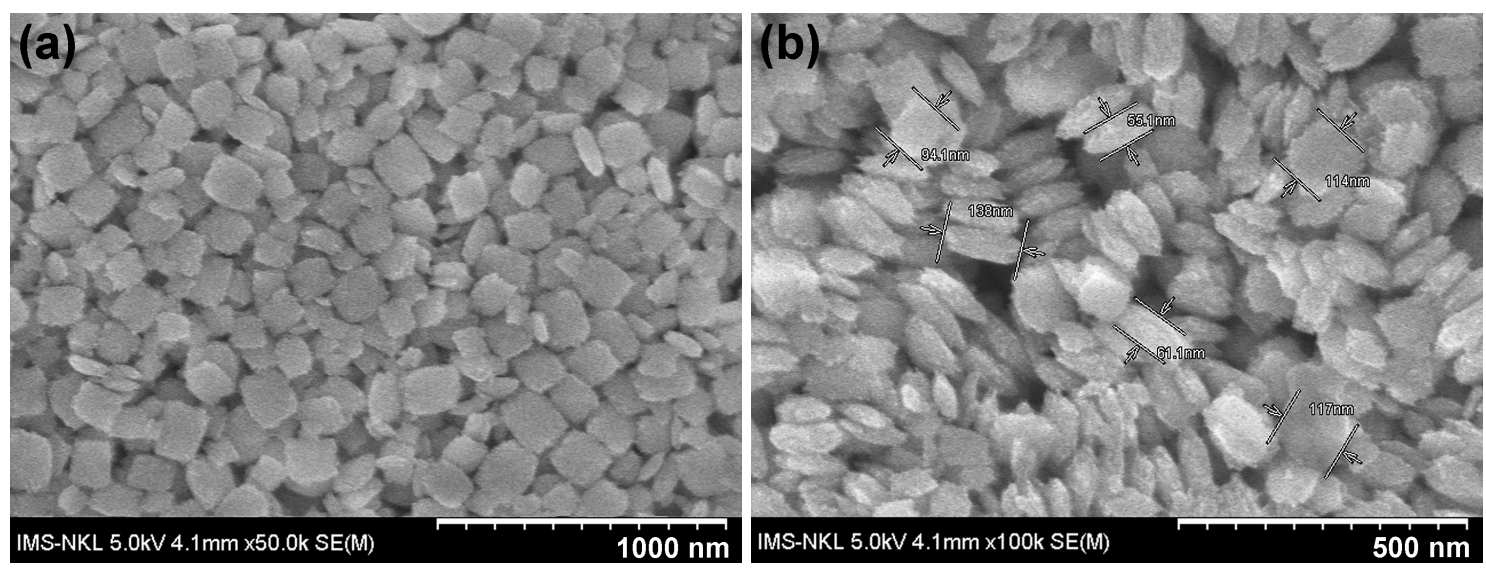

Fig. 2. FESEM images of purified CZPs deposited on glass slide observed at (a): $\times 50000$ and (b): $\times 100000$ magnifications.

with very low polydispersity index (0.071) and the colloidal particles sizes are in the range of 80 $-300 \mathrm{~nm}$.
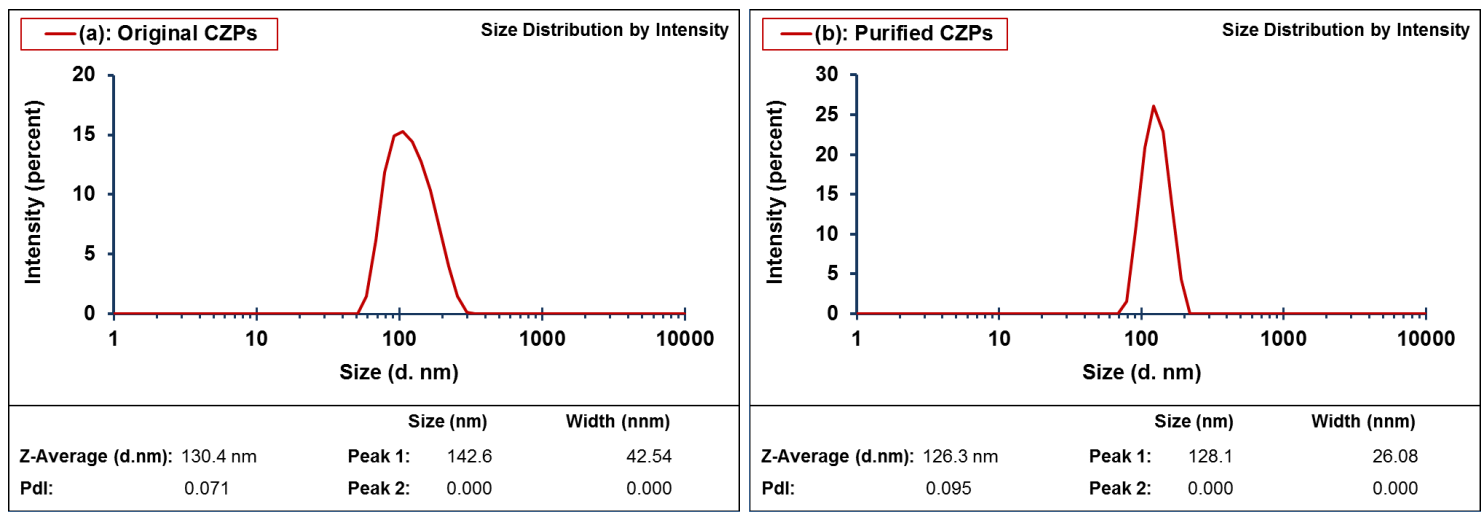

Fig. 3. DLS diagram of (a): original CZPs and (b): purified CZPs at $1 \mathrm{wt} . \%$ concentration.

\section{III.3. XRD study}

The XRD patterns of the dried CZPs and calcined CZPs (at $450^{\circ} \mathrm{C}$ for $6 \mathrm{~h}$ ) are shown in Fig. 4. The XRD pattern of dried CZPs show some very broad peaks centered at around $2 \theta=31^{\circ}$, $49^{\circ}$ and $55^{\circ}$. This pattern can be assigned to low crystalline degree of hydrous $\mathrm{ZrO}_{2}\left(\mathrm{ZrO}_{2} \cdot \mathrm{nH}_{2} \mathrm{O}\right)$. The XRD pattern of calcined CZPs shows some main visible peaks at $2 \theta=24.25^{\circ}, 28.25^{\circ}, 31.25^{\circ}$, $34.15^{\circ}, 41.15^{\circ}, 49.05^{\circ}, 50.15^{\circ}, 55.45^{\circ}$ and 60.45 , which are characteristic for monoclinic crystal structure of zirconia [21]. This XRD pattern proves that pure monoclinic crystal structure of zirconia can be prepared at calcination temperature of $450^{\circ} \mathrm{C}$. 

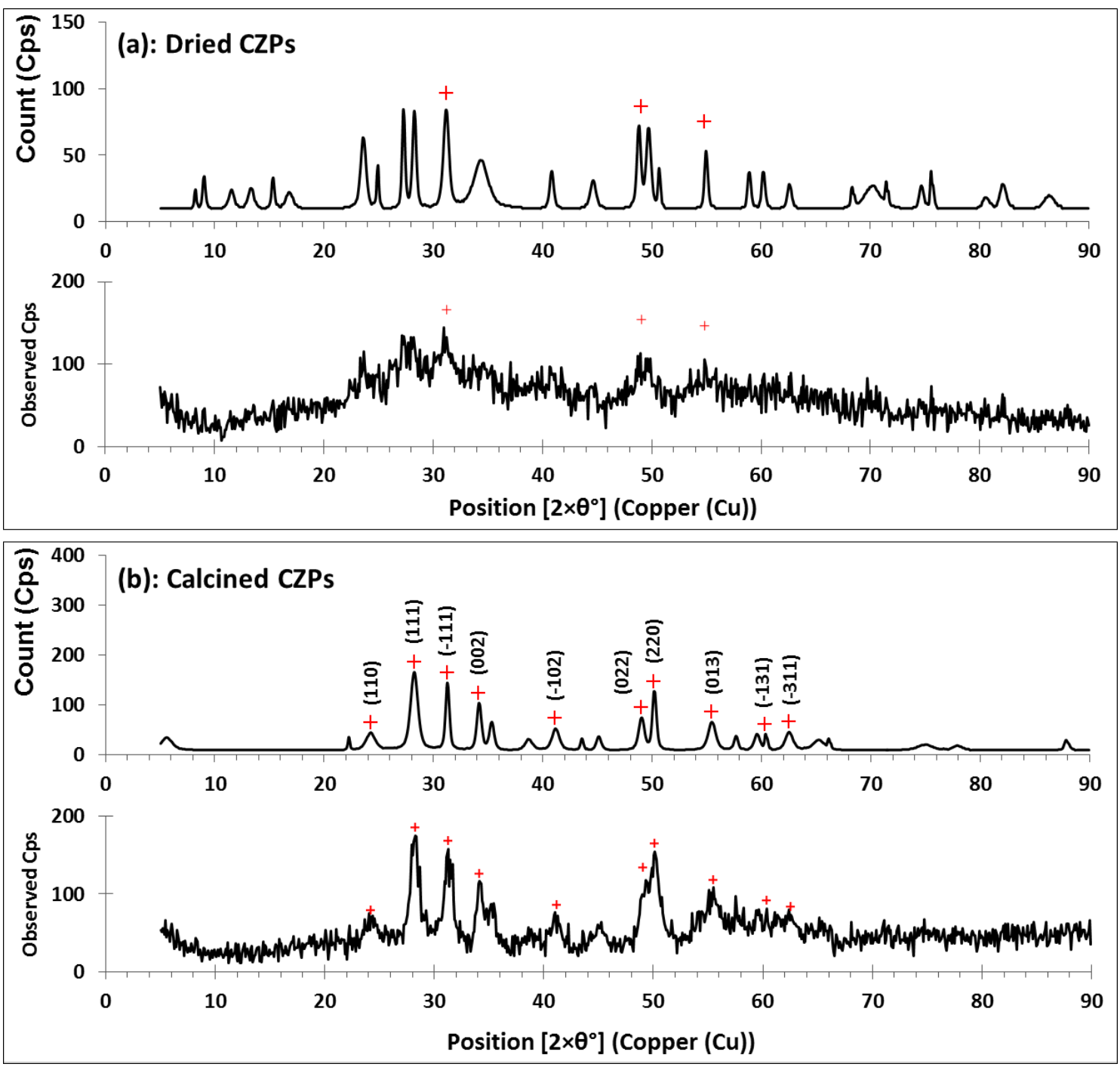

Fig. 4. XRD patterns of (a): dried CZPs and (b): calcined CZPs in powder forms.

\section{III.4. TGA study}

The TGA curve of dried CZPs in Fig. 5 shows the mass loss due to the dehydration of hydrous zirconia. At $700^{\circ} \mathrm{C}$, the total mass was reduced by $21.86 \%$. In other words, the zirconia content in the solid phase is $78.14 \%$, and molecular formula of hydrous zirconia can be found as $\mathrm{ZrO}_{2} .2 \mathrm{H}_{2} \mathrm{O}$. The DTA curve, Fig. 2, shows an endothermic peak at $115^{\circ} \mathrm{C}$ with end-set point at about $332^{\circ} \mathrm{C}$, which corresponds to the reaction of $\mathrm{ZrO}_{2} \cdot 2 \mathrm{H}_{2} \mathrm{O}$ to $\mathrm{ZrO}_{2} \cdot 0.5 \mathrm{H}_{2} \mathrm{O}$, with experimental results of $16.78 \%$ (theoretically is $17 \%$ ). Therefore, Eq. (1) can be rewritten as Eq. (3) as followed:

$$
\mathrm{ZrOCl}_{2}+3 \mathrm{H}_{2} \mathrm{O} \rightarrow \mathrm{ZrO}_{2} \cdot 2 \mathrm{H}_{2} \mathrm{O}+2 \mathrm{HCl}
$$




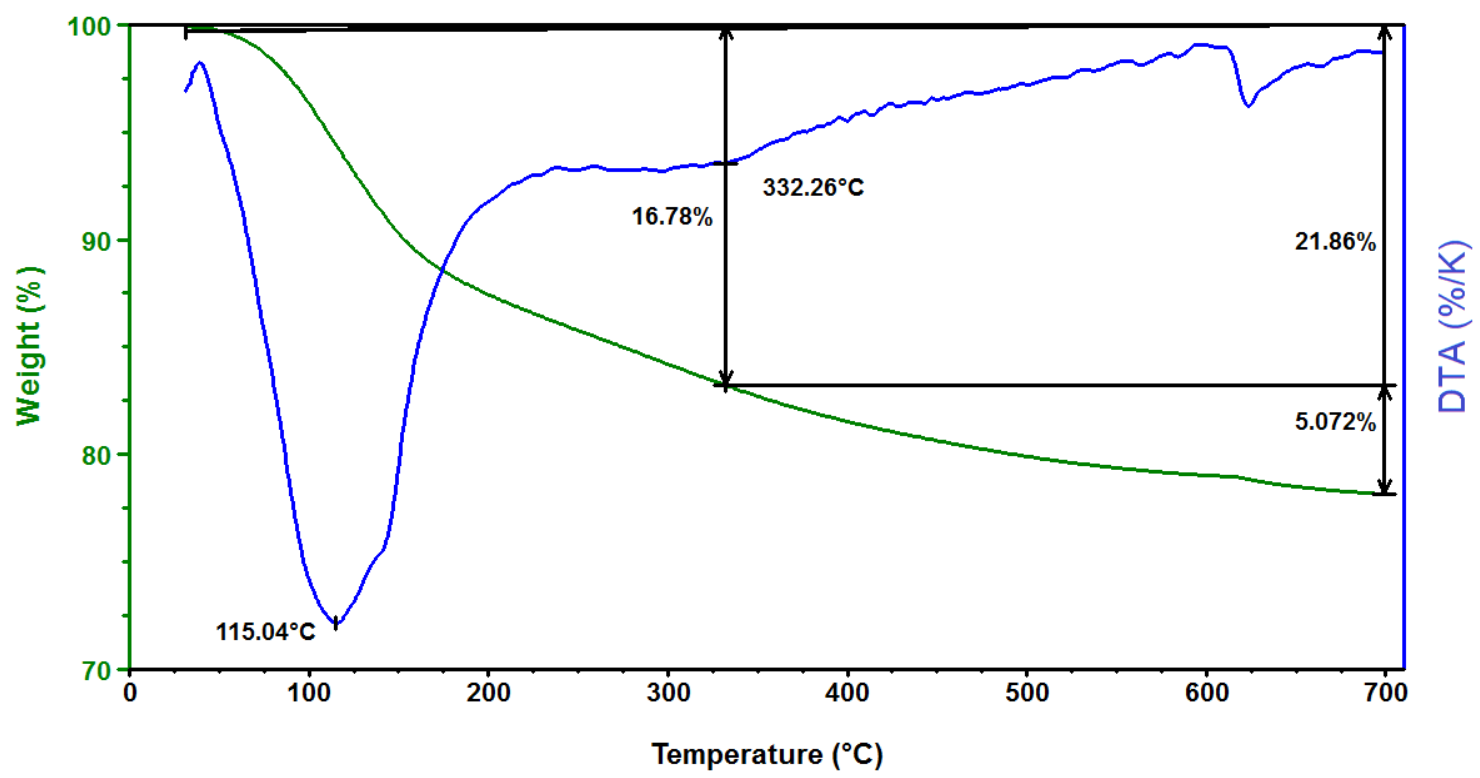

Fig. 5. Thermal gravimetric analysis of the dried CZPs obtained from hydrous zirconia suspension.

\section{CONCLUSIONS}

Hydrous CZPs were stabilized by using $\mathrm{HCl}$ in aqueous solution at $\mathrm{pH}=6$. The DLS and FESEM characterizations showed the monodispersion of CZPs with very low polydispersity index, CZPs are in sheet-like shape with size ranges from 70 to $140 \mathrm{~nm}$ in length and about $40-60 \mathrm{~nm}$ in thickness. FTIR indicated the presence of $\mathrm{Zr}-\mathrm{OH}$ groups and hydrated structure of dried CZPs powder. XRD indicated the semicrystal structure of CZPs in the suspension. TG analysis proved the formulation of hydrous zirconia is dihydrated zirconia $\left(\mathrm{ZrO} \cdot 2 \mathrm{H}_{2} \mathrm{O}\right)$. This kind of colloidal will be further studied towards application in the field of polymer nanocomposites.

\section{ACKNOWLEDGEMENTS}

This research is funded by Vietnam Academy of Science and Technology (VAST) under grant number VAST03.05/20-21.

\section{REFERENCES}

[1] C. Piconi, G. Maccauro, Biomaterials 20 (1999) 1.

[2] M. C. S. Sajjan, An overview on Zirconia, In: Trends in prosthodontics and implantology, 2015.

[3] K. Matsui, M. Ohgai, J. Am. Ceram. Soc. 84 (2001) 2303.

[4] I. Chepurna, V. Kanibolotsky, V. Strelko, J. Sol-Gel Sci. Technol. 68 (2013) 500.

[5] C. Huang, Z. Tang, Z. Zhang, J. Am. Ceram. Soc. 84 (2001) 1637.

[6] H. Vesteghem, I. Charissou, H. Reverón, Key Eng. Mater. 132-136 (1997) 129.

[7] Z. Zhao, D. Chen, X. Jiao, J. Phys. Chem. C111 (2007) 18738.

[8] K. Vernieuwe, P. Lommens, J. C. Martins, F. Van Den Broeck, I. Van Driessche, K. De Buysser, Materials (Basel) 6 (2013) 4082.

[9] M. Aghazadeh, A.-A. M. Barmi, M. Hosseinifard, Mater. Lett. 73 (2012) 28. 
[10] J. Markoviæ, S. Milonjic, J. Serbian Chem. Soc. 71 (2006).

[11] M. Aghazadeh, A.-A. M. Barmi, M. Hosseinifard, Mater. Lett. 73 (2012) 28.

[12] J. Livage, Catalysis Today 41 (1998) 3.

[13] M. Prica, S. Biggs, F. Grieser, T. W. Healy, Colloids Surf. A Physicochem. Eng. Asp. 119 (1996) 205.

[14] B. Jachimska, Z. Adamczyk, J. Eur. Ceram. Soc. 27 (2007) 2209.

[15] N. F. Amat, A. Muchtar, M. J. Ghazali, N. Yahaya, Ceramics Inter. 40 (2014) 5413.

[16] K. L. Chen, A. Chiang, H. K. Tsao, J. Nanoparticle Res. 3 (2001) 119.

[17] G. Pang, E. Sominska, H. Cölfen, Y. Mastai, S. Avivi, Y. Koltypin, A. Gedanken, Langmuir 17 (2001) 3223.

[18] C. Guo, P. Hu, L. Yu, F. Yuan, Mater. Lett. 63 (2009) 1013.

[19] H. Yue-xiang, G. Cun-ji, Powder Technology 72 (1992) 101.

[20] A. V. Kostrikin, F. M. Spiridonov, L. N. Komissarova, I. V. Lin'ko, O. V. Kosenkova, B. E. Zaitsev, Russian Journal of Inorganic Chemistry 55 (2010) 866.

[21] P. R. Rauta, P. Manivasakan, R. Venkatachalam, B. B. Sahu, B. Panda, P. Mohapatra, Phase Transitions 85 (2012) 13. 